\title{
A BUSCA POR RESPOSTA CONSTITUCIONALMENTE ADEQUADA VERSUS DISCRICIONARIEDADE: A CONCRETIZAÇÃO DE DIREITOS OU INTERESSES?
}

\author{
THE SEARCH FOR CONSTITUTIONALLY ADEQUATE RESPONSE \\ VERSUS DISCRETION: THE REALIZATION OF RIGHTS OR INTERESTS?
}

Patrícia Maino Wartha*

Resumo: $\mathrm{O}$ conjunto normativo tem sentido próprio, inadmitindo atribuições extensivas ou restritivas, e, embora isso pareça elementar, cotidianamente alguns intérpretes e julgadores, discricionariamente, atribuem sentido aquém ao texto constitucional, o que inviabiliza o encontro da resposta constitucionalmente adequada, ao passo que viabilizam a concretização de interesses mascarados de direitos. Nesse liame, a "crítica hermenêutica do Direito" proposta por Streck a partir da fenomenologia hermenêutica, que abarca a hermenêutica filosófica de Heidegger e Gadamer, torna-se imprescindível ao fidelizar os sentidos em si mesmos, uma vez que os intérpretes não devem determinar a solução adequada ao caso concreto, e sim a norma.

Palavras-chave: Hermenêutica. Constituição. Discricionariedade. Direitos.

\begin{abstract}
The set of rules have a proper sense, not accepted assignments extensive or restrictive, and although this sounds basic, everyday some interpreters and judges, in its discretion, assign meaning behind the constitutional text, which makes the meeting of the constitutionally appropriate response, while enable the realization of rights vested interests. In this bond, the "critical hermeneutics of law" proposed by Streck from hermeneutic phenomenology, which encompasses the philosophical hermeneutics of Heidegger and Gadamer, it is essential to retain the senses themselves, since the interpreters should not determine the adequate solution to the case, but the norm.
\end{abstract}

Keywords: Hermeneutics. Constitution. Discretion. Rights.

* Mestre em Direito Público pela Unisinos, doutoranda em qualidade ambiental pela Feevale, advogada, docente e coordenadora do núcleo de práticas jurídicas do Centro de Ensino Superior Cenecista de Farroupilha. E-mail: adv.patriciamw@gmail.com. 
Em uma era repleta de incertezas, frente a conflitos de interesses que conferem significado diverso para o ordenamento jurídico, urge-se por resgatar a essência de conceitos basilares. Para tanto há de se trabalhar com o real, o concreto, abdicando-se de subjetivismos e discricionariedades. É exatamente nesse resgate ao caso concreto que se encontra a reflexão hermenêutica (HÄBERLE, 2002, p. 0910,40 e 48) abrindo caminhos para se alcançar uma solução constitucionalmente adequada.

Muito se discute a respeito da existência de múltiplas respostas e soluções, considerando, pois, a discricionariedade dos intérpretes. Contudo, abdicando-se de atribuição de sentido à norma, será que é possível manter essa multiplicidade de soluções?

Nessa busca por soluções e respostas que contemplem a complexidade da atualidade, Cittadino idealiza a promulgação da Constituição Cidadã, pois em sua visão, é a expressão definitiva deste movimento de retorno ao direito. Trata-se de pretensão de reencantar o mundo. "Seja pela adoção do relativismo ético na busca do fundamento da ordem jurídica, seja pela defesa intransigente da efetivação do sistema de direitos e do papel do judiciário" pretendendo se resgatar a força do direito. Os encarregados disso são os Constitucionalistas "comunitários". A estudiosa propõe ainda que a realização dos valores constitucionais dependa de uma comunidade de intérpretes e mecanismos processuais, de uma hermenêutica constitucional que ultrapasse o formalismo positivista (CITTADINO, 2004, p. 14, 63-64).

Peter Häberle propõe a adoção de uma hermenêutica constitucional adequada à sociedade pluralista ou à chamada sociedade aberta, devendo o processo constitucional tornar-se parte do direito de participação democrática. Consoante Häberle, "A sociedade é livre e aberta na medida que se amplia o círculo de intérpretes da Constituição em sentido lato". Nesse viés: "Devem ser desenvolvidas novas formas de participação das potências públicas pluralistas enquanto intérpretes em sentido amplo da Constituição. O direito processual constitucional torna-se parte do direito de participação democrática". Sobretudo, há de se ter cautela quanto à efetiva democratização da concretização de "direitos" e não de "interesses" quando se admitem interpretações diversas e por vezes arbitrárias do texto constitucional.

Para tanto, o resgate ao caso concreto torna-se condição de possibilidade, sendo necessário, pois, recuperar, nas palavras de Stein, o "verdadeiro ambiente" (STEIN, 2008, p. 10), haja vista o mundo prático ter sido "sequestrado metafisicamente pelas diversas posturas epistemo-metodológicas", na expressão de Streck (STRECK, 2008, p. 5, 10-11). 
Daí a necessidade da elaboração de uma crítica à hermenêutica jurídica tradicional - ainda (fortemente) assentada no paradigma objetificante da filosofia da consciência - através dos aportes aproximativos da semiótica (teoria geral da significação) e da hermenêutica filosófica, com ênfase na segunda, pela qual o horizonte do sentido é dado pela compreensão (Heidegger) e ser que pode ser compreendido é linguagem (Gadamer), onde a linguagem não é simplesmente objeto, e sim horizonte aberto e estruturado e a interpretação faz surgir o sentido (STRECK, 2008, p. 18-19 e 403).

Por tudo isso baliza sua doutrina na hermenêutica filosófica referenciando-a como herdeira da filosofia hermenêutica de Martim Heidegger e (STRECK, 2010, p. 23).

A partir dessa nova crítica do Direito, balizada na fenomenologia hermenêutica, torna-se possível o encontro de respostas que promovam a efetividade do constitucionalmente previsto à medida que resgata o caso concreto onde o modo prático de ser no mundo define a compreensão (STRECK, 2008. p. 12 e 413), especialmente em se tratando da realidade brasileira, amplamente contextualizada por Streck.

Muito embora se pense que o próprio texto constitucional sugira o confronto entre direitos, deve-se ter em mente que a Constituição Federal destina-se ao social, ao todo. Contudo, tensões e conflitos são elementares quando se está disposto a uma sociedade composta por indivíduos e seus distintos interesses e, assim sendo, há de se ter muita cautela quando é atribuída a nomenclatura de direitos a meros interesses.

\section{DIREITOS OU INTERESSES: DISCRICIONARIEDADE OU CASO CONCRETO?}

A Constituição Federal de 1988 elenca uma vasta gama de direitos, e muitos deles carentes de concretização, sendo, portanto, justa e imprescindível a reivindicação para que se cumpram. Todavia, ao se atribuir sentido ao texto constitucional, eivando-o de subjetividade, transformam-se esses direitos em meros interesses, que não constam no regramento da carta federal.

O texto constitucional foi criado para proteção da coletividade, sendo, pois, em prol do indivíduo, contudo, isso não significa dizer que garante interesses individuais em detrimento do coletivo.

Mesmo que à primeira vista não pareça, é muito tênue a diferença entre o que resguarda a Constituição e o que cada um entende que ela resguarda. Assim, os direitos podem e devem ser respeitados e preservados, e mesmo que os interesses igualmente possam ser concretizados, não podem se sobrepor aos direitos. 
Observa-se, pois, uma confusão entre o que realmente é (direito), o quê parece ser (atribuição de sentido) e o que se gostaria que fosse (interesse). E assim sendo, torna-se indubitável o resgate ao verdadeiro, ao concreto.

Isto posto, passasse a perceber que a verdade, muitas vezes tida por utópica, pode ser alcançável quando se equivale à realidade, ao caso concreto, e nesse sentido, divergindo da veracidade.

Menéndez entende que verdade e veracidade não são sinônimos (MENÉNDEZ, 1995, p. 79), à verdade atribui-se o significado de realidade, ao passo que a veracidade é uma espécie de correspondência do que se diz com quem o diz. Em consequência, enquanto o contrário da verdade ou dos diversos tipos de verdade, é o erro, o contrário da veracidade é a mentira ou o engano. Nesse viés, a veracidade poderia se equivaler à sinceridade.

Sob essa ótica, os interesses representariam a veracidade, enquanto os direitos, a verdade.

Diante do exposto, vislumbra-se a necessidade do abandono à pessoalidade e à subjetividade das relações, que tornam o discricionário arbitrário. E é nesse caminhar que se encontra a hermenêutica, combatendo exatamente esse individualismo exacerbado que resulta em "cegueira"1 (SARAMAGO, 2001 e 2008), na medida em que se esquece a sociedade, o social, e se preconiza somente o indivíduo e sua individualidade cunhada em interesses privados e egoístas, o que resulta em interpretações subjetivas do próprio texto constitucional. A esse respeito, Dumont profere que "A nação é precisamente o tipo de sociedade global correspondente ao reino do individualismo como valor" (DUMONT, 1993, p. 21).

Sob esse olhar, Arruda e Gonçalves discorrem que: "Hermenêutica e ética são termos recorrentes a interpelar os operadores do direito na tarefa de construção de alternativas jurídicas para a democracia" (ARRUDA JÚNIOR; GONÇALVES, 2002, p. 321).

Assim, reitera-se que a hermenêutica vem de encontro à concretização de direitos, não de peculiares interesses. A respeito de direitos, Ingo Wolfgang Sarlet, assevera que os direitos fundamentais não se encontram na esfera da disponibilidade dos poderes públicos, mas assegurá-los é seu dever (SARLET, 2004, p. 327). Isto posto, verifica-se que nada é estabelecido quanto aos interesses, que podem naturalmente serem concretizados, contudo não se enquadram na esfera da indisponibilidade como os direitos.

1 "Cegueira ideológica": denominação adotada por Saramago para explicar os paradigmas que ainda perpetuam e devem ser superados através da opção pela lucidez (SARAMAGO, 2001 e 2008). 

ADEQUADA

A sociedade, dita pós-moderna, constituindo-se pela evolução na complexidade de suas relações sociais, acaba tencionando os processos de tomada de decisões, exigindo um novo paradigma epistemológico, capaz de possibilitar a reestruturação do direito inserido nesse novo contexto social.

O pensamento fundamentado no positivismo lógico já não é suficiente para explicar e fundamentar as relações jurídicas existentes nessa moderna e complexa sociedade. E menos ainda são suficientes teorias e métodos calcados em solipsismos ${ }^{2}$ e para tanto, urge-se por um "novo" sujeito que não se aproprie dos sentidos, como reflete Lenio: [...] a derrocada do modelo de direito e de Estado demanda um "novo" sujeito, mas um sujeito que já não possa "dominar" os sentidos, como se fossem "propriedade sua", enfim, como se os sentidos fossem produtos de sua consciência [...] (STRECK, 2010, p. 03, 08, 10 e 29).

Por certo que, no cenário jurídico atual, e principalmente na sociedade moderna capitalista, para que se encontre uma resposta constitucionalmente adequada, não se trata simplesmente de apresentar um discurso preexistente desprovido de qualquer análise social, cultural ou histórica, como costumeiramente vêm ocorrendo. Por essas razões é que as demandas judiciais estão cada vez maiores, haja vista que essa talvez seja a única maneira de conferir efetividade à Constituição, sendo que em algumas ocasiões nem dessa forma é concretizada.

Laurence Tribe e Michael Dorf trazem a ideia de que a Constituição não é simplesmente o que se quer que ela seja (Tribe e Dorf, 2007, p. 12) , embora $^{3}$ reconheçam que as decisões são eivadas de subjetividade. Para tanto propõem que "Temos que encontrar princípios de interpretação que possam ancorar a Constituição em uma realidade externa mais segura e determinada. E essa tarefa não é simples" (TRIBE; DORF, 2007, p. 13).

Denota-se, pois, que os conflitos que são sugeridos no ordenamento também o são por conta da subjetividade na atribuição de sentidos. Assim refere Eros Grau ${ }^{4}$ retratando exatamente o tido por hermeneuticamente adequado, disciplinando

2 O termo solipsista é utilizado por Lenio Luiz Streck para designar um sujeito que faz uso de seu próprio juízo para decidir, ou seja, de forma subjetiva ou mais que subjetiva. Disponível em: <http://www. juridicobrasil.com.br/portal/index.php?tipo=7\&cod=2\&id_entrevista=11 >. Acesso em: 5 nov. 2009.

3 No mesmo sentido ver BOBBIO, 1995, p. 41.

4 Eros Grau, em seu julgamento na ADPF 144 do Supremo Tribunal Federal, ressalta que por mais que não se fale em supremacia do público em relação ao privado, deve-se fielmente observar o princípio da soberania popular e da democracia representativa. 
que "ninguém está autorizado a ler na Constituição Federal o que lá não está escrito", a Constituição não pode ser reescrita conforme a necessidade ocasional do intérprete.

Em se preconizando a concretização dos direitos previstos no texto constitucional, necessita-se de aplicação do mesmo texto em seu real sentido. Nesse aporte, com recurso à hermenêutica filosófica e à crítica hermenêutica do Direito, proposta por Streck, se vislumbra que a compreensão/interpretação não pode ser vista como um procedimento em que o intérprete escolhe qual a melhor resposta, assim como ele também não pode dizer qual caso é simples e qual caso é difícil, em vista do banimento à subjetividade incutido nessa classificação (STRECK, 2008, p. 12), e exatamente por não admitir essa discricionariedade é que se torna possível alcançar a resposta constitucionalmente adequada para o caso concreto.

Acerca da eficácia da crítica hermenêutica do direito assevera Lenio:

[...] a hermenêutica filosófica, adaptada ao que venho denominando de Crítica Hermenêutica do Direito, pretende ir além dos discursos prévios de fundamentação trazidos pelas teorias discursivas como solução para o problema da subjetividade (e, portanto, da discricionariedade) do juiz. Como o direito é um saber prático e que deve servir para resolver problemas e concretizar os direitos fundamentais-sociais que ganharam espaço nos textos constitucionais, a superação dos obstáculos que impedem o acontecer do constitucionalismo de caráter transformador estabelecido pelo novo paradigma do Estado Democrático de Direito pressupõe a construção das bases que possibilitem a compreensão do estado da arte do modus operacional do direito (STRECK, 2010, p. 11-12).

Nesse aporte à concretização constitucional e banimento à subjetividade do intérprete, mais precisamente quanto à discricionariedade, Freitas revela que "De fato, o exercício da discricionariedade administrativa pode resultar viciado por abusividade (arbitrariedade por excesso) ou por inoperância (arbitrariedade por omissão)" (FREITAS, 2007, p. 62) e que “[...] quanto mais se estiver preocupado com os propósitos ativos da Constituição, menor será o risco de subjetivismo excessivo dos intérpretes [...]" (FREITAS, 2009, p. 33-34).

Ainda, a respeito da discricionariedade Streck vai referi-la como ausência de "controle" na interpretação e nas decisões judiciais, resultante em decisionismos, em que os intérpretes, e especialmente os julgadores, determinam qual a solução adequada a cada caso, e incorrendo por vezes em individualismo e subjetivismo, ou seja, julgando conforme os seus convencimentos, transmitem decisões arbitrárias, haja vista que a decisão deve-se pautar unicamente na Constituição (STRECK, 2010, p. 09-10). 
A discricionariedade se dá através da liberdade interpretativa, consoante Streck, "onde, no fundo, queiramos ou não, cada juiz decide como quer (arbitrariamente), de acordo com a sua subjetividade (esquema sujeito-objeto)", o que pode incorrer em decisionismos e arbitrariedades. Explica ainda que esse "ir-além-do-texto", advém de diversas teorias "que colocam na subjetividade do intérprete o locus do processo hermenêutico, tais como as teorias realistas e axiologistas em geral, [...] que, quando lhes interessa, relegam os textos jurídicos a um plano secundário, sob o pretexto de que "cabe ao intérprete a descoberta dos valores escondidos embaixo do texto"” (STRECK, 2010, p. 09-10).

Nessa perspectiva, observam-se alguns doutrinadores que propõem diferentes formas ${ }^{5}$ de interpretação como teorias procedimentalistas, ${ }^{6}$ o uso de ponderação (ALEXY, 1989; ATIENZA, 2002, p. 267), dedução, ${ }^{7}$ proporcionalidade (SCHMITT, 2000, p. 217-218), enfim, que se utilizam de diversas técnicas e métodos para a resolução de litígios, todavia incorrendo na atribuição de discricionariedade ao julgador, embora algumas delas até pretendessem limitá-la ${ }^{8}$.

5 Tribe e Dorf fazem alusão a outra forma de interpretação e/ou aplicação da Constituição, exemplificando a perspectiva adotada por Dworkin, que segundo os estudiosos consistiria em extrair o "melhor" do texto, devendo captar a visão mais ampla possível, no entanto essa perspectiva tão aberta traz complexidades, já que afirmam eles "a linha entre o que se pensa que a Constituição diz e aquilo que se gostaria que ela dissesse, torna-se tão tênue que é extraordinariamente difícil mantê-la." E explicam que essa forma de compreensão incorre em erro visto que a ambiguidade do texto da Constituição, indeterminações históricas, e a própria linguagem que por vezes expressa uma leitura diversa da pretendida (TRIBE; DORF, 2007, p. 30). Trazendo a perspectiva de Dworkin, observa-se que em sua obra "O Império do Direito" que traz a ideia de que "somos súditos do império do direito", sintetiza seu entendimento ao afirmar que "o raciocínio jurídico é um exercício de interpretação construtiva, de que nosso direito constitui a melhor justificativa do conjunto de nossas práticas jurídicas, e de que ele é a narrativa que faz dessas práticas as melhores possíveis" (DWORKIN, 1999, p. XI).

6 Lenio se pronuncia a cerca da insuficiência das teorias procedimentalistas, do paradigma representacional-metodológico e das teorias argumentativo-discursiva: "Em outras palavras, é a incindibilidade entre interpretar e aplicar que irá representar a ruptura com o paradigma representacionalmetodológico". (p. 14) [...] “Nesse sentido, a tese da resposta constitucionalmente adequada (ou a resposta correta para o caso concreto) pressupõe uma sustentação argumentativa. A diferença entre hermenêutica e a teoria argumentativo-discursiva é que àquela trabalha com uma justificação do mundo prático, ao contrário desta, que se contenta com uma legitimidade meramente procedimental" (STRECK, 2010, p. 26).

7 Maccormick propõe em sua obra que os casos distinguem-se em fáceis e difíceis, easy e hard cases, para os casos fáceis julga-se conforme a dedução, subsunção, pura e simplesmente, sendo que, somente os difíceis pressupõem análise. Tese repleta de críticas, haja vista que, a pura e simples distinção entre easy e hard cases revela por si só a discricionariedade intrínseca nesse método interpretativo (Maccormick, 2006).

${ }^{8} \quad$ Streck refere que a teoria da argumentação faz uso da subjetividade do intérprete (filosofia da consciência), diferentemente da hermenêutica: "Eis aqui a diferença entre a hermenêutica e a teoria da argumentação: enquanto a teoria da argumentação compreende os princípios (apenas) como mandados de otimização, portanto, entendendo-os como abertura interpretativa, o que chama à colação, necessariamente, 
A respeito de teorias que fazem uso de métodos, é imprescindível referir Gadamer que vai se expressar exatamente contra o "método" em sua obra "Verdade e método", haja vista que, o que deve ser trabalhado é o mundo prático de ser no mundo, a existência concreta, pois são esses que determinam a compreensão. ${ }^{10}$ Nesse sentido, Lenio afirma que não é contra teorias procedimentais, discursivas ou argumentativas, que possuem recepção no campo da operacionalidade do direito, todavia "o modo de ser manifestativo da compreensão precede a teoria do conhecimento", o que confere muitas objeções a essas teorias e procedimentos (STRECK, 2008, p. 12 e 15).

Lenio, a respeito dessas múltiplas formas e procedimentos de interpretação, vai dizer que acabam incorrendo no que exatamente criticam:

[...] a pretexto de superar as diversas formas assumidas pelo positivismo jurídico e buscando resolver os problemas da impossibilidade de antevisão de todas as hipóteses de aplicação próprias de um direito que assumia um caráter inexoravelmente hermenêutico, apostaram na construção de discursos (prévios) de justificação/fundamentação (Begründungsdiskurs), com o que acabaram por incorrer na própria problemática que pretendiam criticar no positivismo $[\ldots]^{11}$ (STRECK, 2010, p. 03).

a subjetividade do intérprete (filosofia da consciência), a hermenêutica - como já referido à saciedade parte da tese de que os princípios introduzem o mundo prático no direito, 'fechando' a interpretação, isto é, diminuindo, ao invés de aumentar, o espaço da discricionariedade do intérprete. Claro que, para tanto, a hermenêutica salta na frente para dizer que, primeiro, são incindíveis os atos de interpretação e aplicação (com o que se supera o método) e, segundo, não há diferença estrutural entre hard cases e easy cases". (STRECK, 2008, p. 182). Por outro lado, incorrendo em discricionariedade, observa-se a perspectiva de Ronald Dworkin ao definir o Direito: “O Direito é um conceito interpretativo. Os juízes devem decidir o que é o direito interpretando o modo usual como os outros juízes decidiram o que é o direito". "Portanto, minha descrição abstrata do objetivo mais geral da interpretação pode muito bem reforçar, para muitos leitores, a tese cética de que é um erro filosófico supor que as interpretações podem ser certas ou erradas, verdadeiras ou falsas" (DWORKIN, 1999, p. 96 e 488).

9 Gadamer refere a filosofia hermenêutica como uma negação da racionalidade metodológica (GADAMER, 2002, p. 564).

${ }^{10}$ Gadamer explica a necessidade da "arte de compreender e de tornar compreensível". Assevera ainda que "Quando comecei a elaborar uma hermenêutica filosófica, sua própria pré-história exigia que se tomassem as ciências 'da compreensão' como ponto de partida” (GADAMER, 2002, p. 563 e 564).

11 A respeito das inúmeras teorias e procedimentos existentes que tentam apresentar respostas corretas, profere Lenio: "É difícil caracterizar as teses decisionistas (discricionárias). Aqui parece adequada - e essa posição é aqui adotada - a noção "forte" de discricionariedade cunhada por Dworkin (Taking Rights Seriously. Massachusetts: Harvard University Press, 1978), para criticar as posturas positivistas. De qualquer modo, assim como é difícil fazer um quadro acerca de (todas) as modalidades de positivismo, também é complexo delinear as posturas decisionistas, que vão desde o normativismo kelseniano, que atribui ao juiz, nos casos difíceis, um poder absoluto, até as tese da escola de direito livre e do realismo norte-americano, passando por Herbert Hart (The Concept of Law. Oxford: Oxford University Press, 1997) alvo principal das críticas 
Observe-se aqui, a reflexão de Canotilho ${ }^{12}$ a cerca da decisão adequada quando, em seu ver, ocorre colisão entre direitos fundamentais, avaliando, como critério mais indicado para a solução do conflito a "prevalência aos direitos fundamentais menos limitados", estabelecendo ainda como uma das viáveis alternativas a ponderação ${ }^{13}$ de valores.

Todavia, sob o viés da ponderação, baseada na busca por equilíbrio na preservação de ambas as searas conflitantes, há de se combater a discricionariedade que se faz presente na medida em que o julgador "determina" o consenso entre as esferas colidentes, de modo, por vezes, a modificar a própria essência dos direitos em colisão. ${ }^{14}$

de Dworkin. A partir de tais autores e posturas, forjou-se um enorme contingente de concepções que têm no esquema sujeito-objeto o seu suporte epistemológico (embora isso não seja confessado por um considerável número de posturas que pretendem criticar o positivismo jurídico)” (STRECK, 2010, p. 03 e 06).

12 Canotilho explica que as colisões entre direitos fundamentais ocorrem quando o exercício de um direito fundamental por parte de um titular evita ou dificulta o exercício de outro direito fundamental por parte de outro titular, considerando, portanto, existir um autêntico confronto entre direitos fundamentais quando o exercício de direitos fundamentais colide entre titulares (CANOTILHO, 2001, p. 12-27). Também sobre o assunto FARIAS, 1996.

13 Robert Alexy que doutrina a cerca da ponderação de princípios, classifica colisão de direitos fundamentais em sentido estrito e colisão de direitos fundamentais em sentido amplo. Em sentido estrito, a colisão entre direitos fundamentais atua quando o exercício de um direito fundamental de um titular projeta efeitos negativos sobre direitos fundamentais de outros titulares de direitos fundamentais, coincidentes ou díspares. De outra monta, a colisão de direitos fundamentais em sentido amplo estabelece-se quando estão em conflito direitos individuais e bens coletivos constitucionalmente protegidos. Ocorre então a colisão quando ocasionalmente algo é vedado por um princípio, mas permitido por outro, momento em que um dos princípios deve recuar. Em determinada circunstância, um princípio cede a outro, em outra situação, a questão da prevalência resolve-se de forma contrária. As circunstâncias de prevalência podem variar nos casos concretos. $\mathrm{O}$ autor alemão expõe a lei de colisão: "La determinación de la relación de precedencia condicionada consiste en que, tomando en cuenta el caso, se indican las condiciones bajos las cuales un principio precede al outro. Bajo otras condiciones, la cuestion de la precedencia puede ser solucionada inversamente" (ALEXY, 1999, p. 86, 91-92). Determinando como adequada a utilização da ponderação, Alexy discorre que as melhores soluções surgem quando se põe opiniões divergentes em dialeticidade, tendo como ponto de partida um consenso acerca da possibilidade de se chegar a uma concordância. A concordância pressupõe a preservação do princípio confrontado, sem o detrimento de um em relação ao outro. A relação de coordenação estabelecida entre os valores dos princípios impedem o aniquilamento de um defronte a outro. Nesse viés, a ponderação dos princípios se dá sem a exclusão daquele que não prevaleceu. Os juízes e os tribunais são os encarregados de estabelecer em cada caso concreto o desejado equilíbrio entre privacidade e publicidade, como no caso em pauta. Constata-se então a presença da discricionariedade, na medida em que atribui ao juiz a tarefa de estabelecer, ponderar, para o alcance do equilíbrio do ordenamento (ALEXY, 1999, p. 67-69).

14 Streck discordando da ponderação profere que: "Penso, aqui, que o calcanhar de Aquiles da ponderação - e, portanto, das diversas teorias argumentativas (e suas derivações) - reside no deslocamento da hierarquização 'ponderativa' em favor da 'subjetividade' assujeitadora do interprete [...] Isso é assim porque a ponderação implica essa 'escolha' subjetiva. [...] No fundo, volta-se, com a ponderação, ao problema tão criticado da discricionariedade. [...] De forma discordante, entendo que a ponderação vem 
Diferentemente, a fenomenologia hermenêutica propõe a ideia de que "entre texto e sentido do texto (norma) não há uma cisão" (STRECK, 2008, p. 407), contrariamente a outras teorias como as argumentativas, que possuem um cunho axiológico, já que deixam margem ao intérprete para decidir subjetivamente.

Além da discricionariedade, a repugnância a conceitos universalizantes também é constatada, Laurence Tribe e Michael Dorf afirmam que "Grande parte das pessoas já perdeu a fé nas ideias de eterno, universal e verdade inquestionável. Mas de alguma forma, na sua maneira comum de viver, ainda conseguem distinguir entre o que parece um argumento bom e o que parece sofisma" (TRIBE; DORF, 2007, p. 18). E asseveram que "é importante apresentar argumentos significativos em um mundo bombardeado com verdades de última hora" (TRIBE; DORF, 2007, p. 19). ${ }^{15}$

Já não são mais cabíveis mitos de verdade desprovidos de qualquer questionamento, premissas calcadas em subjetivismos que desencadeiam confrontos entre interesses, a pluralidade e a complexidade inerentes à sociedade contemporânea necessitam de objetividade, impessoalidade e verdade que predominem em todas as relações e principalmente na resolução de conflitos.

Para tanto, se torna imprescindível a existência de argumentos constitucionais, sendo inestimável a busca pelo desvelamento do que a Constituição realmente significa e determina ao caso concreto ${ }^{16}$.

Nesse sentido, de pretender desvendar o significado da Constituição, Carl Schmitt profere que "Mas onde não se pode mais diferenciar o que é guerra e o que é paz, ai fica mais difícil de dizer o que é neutralidade" (SCHMITT, 1992, p. 138). Ou seja, diante de um ordenamento em que se perderam os conceitos básicos essenciais em meio a subjetividades e discricionariedades dos diversos intérpretes, como saber qual a resposta adequada para a resolução dos conflitos? Desta monta, depreendese a urgente necessidade de conhecer, ou resgatar, os verdadeiros significados para que efetivamente se encontre uma resposta constitucionalmente adequada.

a ser o mecanismo exterior pelo qual se encobre o verdadeiro raciocínio (estruturante da compreensão). [...] Assim, o 'remédio' contra a ponderação é um remédio contra um mecanismo de encobrimento de um raciocínio que se faz incompleto, porque é sobre o equívoco de duas situações que se decidem sobre a ponderação, que, assim, retorna ao método" (STRECK, 2008, p. 181-182).

15 Nesse sentido, Dotti afirma que "o Homem não consegue mais distinguir entre o divino e o profano, entre a realidade e a ficção, entre o verossímil e o absurdo" (DOTTI, 1980, p. 30).

16 Buscar respostas constitucionalmente adequadas significa, nas palavras de Tribe e Dorf: "focar nossa energia interpretativa nos aspectos concretos da Constituição. Para começar a fazer a distinção entre as formas boas e as formas ruins de criar argumentos sobre o que a Constituição significa" (TRIBE; DORF, 2007, p. 19). 
A fenomenologia hermenêutica assume esse desafio, propondo a existência de uma resposta constitucionalmente adequada, para tanto, é imprescindível que o Direito e o Estado superem a crise de paradigma "liberal-individualistanormativista"17, assim denominada por Lenio Luiz Streck, que entende ser possível encontrar respostas $\operatorname{corretas}^{18} \mathrm{em}$ direito por meio do caráter anti-relativista da hermenêutica filosófica, onde o texto procura não se desligar da existência concreta e por isso é dotado de fidelidade à realidade e ao texto constitucional (STRECK, 2009, p. 17-19).

Na expectativa de se alcançar uma solução adequada, Tribe e Dorf proferem que "não existe fórmula capaz de eliminar definitivamente a necessidade de escolhas judiciais", para tanto ensinam que se deve sujeitar todas as decisões e argumentos constitucionais a análises constantes (TRIBE; DORF, 2007, p. 35-37). Ou seja, o texto constitucional deve ser interpretado, discutido, analisado a todo o instante, não resultando em um modelo único e perfeito, frente às pluralidades e multiplicidades do momento atual. ${ }^{19}$

O que se evidencia é que a fenomenologia hermenêutica resgata, além da realidade prática, a esperança no ordenamento jurídico e na Administração Pública, demonstrando que há uma resposta correta no sentido de uma resposta constitucionalmente adequada, ou ao menos que, em se discutindo e analisando o caso concreto, desvencilhando-se de pré-conceitos fundados na subjetividade do intérprete/administrador, é possível decidir de forma a evitar decisionismos e abandonar a discricionariedade.

Lenio Luis Streck, ao longo de sua obra "Verdade e Consenso" (STRECK, 2008, p. xxi e 9), trata, entre outros pontos, da impossibilidade da distinção entre fundamentar, compreender e interpretar, ao passo que, ao se fundamentar e interpretar é porque já houve a compreensão, o que à primeira vista parece elementar, no entanto, a maioria das teorias ainda trabalha a distinção entre os mesmos.

${ }^{17}$ Lenio afirma que essa crise de paradigma "liberal-individualista-normativista", institui e é instituída por uma outra crise: crise do paradigma epistemológico da filosofia da consciência, que ainda se cunha na dicotomia sujeito-objeto. E não obstante, refere-se a outra mudança de paradigmas que ainda não se deu no sistema jurídico brasileiro: da filosofia da consciência para a filosofia da linguagem (STRECK, 2009 , p. 18 e 61).

${ }^{18}$ Em contrapartida, Dworkin, no que se refere à existência de uma única resposta constitucionalmente adequada, revela que: "Não afirmei que nunca há um caminho certo, apenas caminhos diferentes, para decidir-se um caso difícil” (DWORKIN, 1999, p. 491).

${ }_{19}$ Nesse viés, Diogo Moreira afirma que: “A boa hermenêutica, contudo, deve ser a doutrinariamente atualizada, para evitar que se interprete o novo com olhos no espelho retrovisor, para usar uma imagem intuitiva" (MOREIRA NETO, 2008, p. 25). 
A hermenêutica filosófica ensina que o "texto" já traz em si mesmo um sentido, que é a pré-compreensão. E é por isso, pelo fato de não ser possível cindir interpretação e aplicação, que se tem uma garantia de que os sentidos não serão atribuídos de forma arbitrária.

Posto isso, a fenomenologia hermenêutica torna-se essencial no resgate ao que o texto constitucional determina ao caso concreto, inadmitindo interpretar qualquer significado de qualquer conteúdo, já que pressupõe desvendar o conteúdo integral do texto, não se restringindo tão somente em descompor vocábulos $(\text { JABUR, 2000, p. 334) })^{20}$.

Nesse aporte, a fragilidade e a insegurança de uma interpretação alicerçada em oscilações entre arbítrio e incertezas é totalmente descabida, não que isso signifique a pressuposição de um Estado absoluto, uma vez que, o Estado moderno não possui tal adjetivo, e caracterizando-se como Estado Democrático de Direito jamais adotará essa denominação de absoluto.

Frente a todas essas questões, o que se revela decisivo, consoante Streck, é:

[...] como transformar a Constituição - e a sua interpretação - em um direito fundamental do cidadão, no sentido de que o resultado dessa interpretação não seja fruto de um sujeito solipsista ou dependente de métodos igualmente elaborados a partir do (velho) paradigma representacional. Este é o cerne da discussão hermenêutica, pois (STRECK, 2010, p. 08).

Quando se almeja uma solução ou resposta, imediatamente e automaticamente o indivíduo avalia o que mais lhe trará benefícios, no entanto, em se tratando de resposta constitucionalmente adequada deve-se esquecer a pessoalidade e a subjetividade e basear-se tão somente em preceitos constitucionais.

Assim, constata-se que a inobservância ou incompreensão do real conteúdo constitucional torna qualquer direito sem sentido. Concomitantemente, a interpretação baseada em determinações abstratas e discricionárias não condiz com a realidade.

Reflete-se, portanto, que diante da incompreensão do que venha a ser e constituir Estado Democrático de Direito, toda a discussão resulta vazia de sentido.

Nessas condições, e frente a tudo o que a Constituição Federal significa, a nova crítica do Direito balizada na hermenêutica filosófica revela-se a possibilidade,

${ }^{20}$ Gilberto ainda discorre que o método de interpretação lógico também carece de eficiência quando apenas empregado em benefício de um preceito de lei isolado, resultando em trabalho inconcluso do intérprete. A interpretação não pode desprezar o sistema (JABUR, 1997, p. 26). 
talvez e provavelmente única, de resgate do que o texto maior quer dizer. A resposta constitucionalmente adequada é a resposta que o ordenamento jurídico e o Estado Democrático de Direito requer e necessita, abdicando de discricionariedades e decisionismos ${ }^{21}$.

Assim, em vista de combater conceitos paradigmáticos asseverados pelo aparelhamento estatal, que se restringem a efetivar somente os direitos que o julgador/administrador julga convenientes, faz-se necessário o recurso à fenomenologia hermenêutica (que abarca a hermenêutica filosófica elaborada por Heidegger e Gadamer), que conseguiu superar os paradigmas até então dominantes ${ }^{22}$.

Partindo da premissa que é totalmente impossível desvencilhar-se de préjuízos e pré-compreensões ${ }^{23}$, a fenomenologia hermenêutica explica que esses devem ser utilizados como início de um processo e não como fim. Aqui se observa o círculo hermenêutico criado por Heidegger e aperfeiçoado por Gadamer, onde a pré-compreensão inicia o processo interpretativo, passando pela compreensão do caso concreto, indo à interpretação e aplicação do real sentido. ${ }^{24}$

Assim torna-se possível o encontro de uma resposta adequada constitucionalmente, sem admissão de subjetividades e de modo ainda a não

${ }^{21}$ Streck vai dizer que: "É possível - e necessário - dizer, sim, que uma interpretação é correta e a outra é incorreta. Movemo-nos no mundo exatamente porque podemos fazer afirmações dessa ordem". [...] “A resposta correta - que não é única e nem uma entre várias - à luz da hermenêutica (filosófica) - será a "resposta hermeneuticamente correta" para aquele caso" (STRECK, 2010, p. 14 e 25).

22 Stein, nesse sentido, explana a cerca das proposições da hermenêutica: "Estamos tentando mostrar o ambiente hermenêutico e preparar uma atmosfera em que se apresentam novas exigências para o pensar. Assim, em lugar de olharmos a hermenêutica apenas como uma nova forma de método, ela já sinaliza no próprio método algo que rompe com o ideal metodológico e epistêmico da modernidade. A hermenêutica traz em si, desde o nascimento do paradigma hermenêutico, uma inclinação para a superação do dualismo da metafísica, da oposição entre sujeito e objeto, do conflito entre representação e sua presentabilidade" (STEIN, 2008, p. 10).

${ }^{23}$ A respeito da questão da compreensão ver STEIN, 2008, p. 43-55. Quanto à pré-compreensão: “As pré-compreensões obscuras, não submetidas à negociação fundamentativa, são também res extra comercio. Colocar em circulação os pontos de vista pré-compreensivos significa disponibilizá-los à interpretação pela qual eles circulam na negociação do sentido. Mantê-los no silêncio dos preconceitos recobertos pelos métodos cientificistas é fugir à negociação" (ARRUDA JÚNIOR; GONÇALVES, 2002, p. 321).

24 A matriz heideggeriana-gadameriana tem como uma das tarefas primordiais a de superar o equívoco das teorias da interpretação, as quais, apesar de reconhecerem que o Direito se caracteriza por um processo de aplicação, permanecem reféns do paradigma metafísico na medida em que propõem a subsunção (Gadamer, 2005, p. 354). 
deixar margem à discricionariedade do julgador, cunhando-se estritamente ao caso concreto e ao conteúdo do texto constitucional.

\section{CONSIDERAÇÕES FINAIS}

Como visto, a fenomenologia hermenêutica atribui objetividade na resolução dos pleitos, à medida que propõe uma resposta constitucionalmente adequada ao caso concreto, combatendo a discricionariedade habitualmente praticada no âmbito jurídico/político, devolvendo assim a esperança em um ordenamento impessoal e com correspondência e fidelidade à Constituição Federal, que é o texto maior, sem atrelamento a subjetivismos e devaneios do momentâneo intérprete ou interesses camuflados de direitos.

Sua consistência revela-se indiscutível, já que a Constituição não pode ser interpretada ao bel prazer de seu intérprete, que no cenário brasileiro, como alerta Streck, cunha-se, em sua grande maioria, no modo metafísico-liberal de interpretação, baseando-se na possibilidade de se extrair a essência das coisas, acreditando que sentidos podem ser retirados do dispositivo legal de forma a desvincular totalmente o sujeito de seu objeto de investigação ${ }^{25}$.

Nesse viés, o desvelar, consoante Lenio, significa "desconstrução/ destruição da tradição jurídica inautêntica, mergulhada na crise de paradigmas" (STRECK, 2009, p. 304), pressupondo-se a superação de inautênticos paradigmas, especialmente o individualista, que oculta o viés social.

Percebe-se então que concretizar a Constituição não é o mesmo que satisfazer interesses, que julgar conforme a discricionariedade do intérprete, que ponderar ou deduzir, pressupõe realidade e análise ao caso concreto consoante preceitos constitucionais e seus verdadeiros significados, para que então se viabilize o encontro da resposta constitucionalmente adequada.

${ }^{25}$ Lenio Luiz Streck trata que os juristas brasileiros ainda fazem uso de um modo metafísico-liberal de interpretação que se baseia na possibilidade de se extrair a essência das coisas, ou seja, por achar que sentidos podem ser retirados do dispositivo legal, de forma a desvincular totalmente o sujeito de seu objeto de investigação e assim conhecê-lo como ele é (p. 17). Ou seja, há uma "crença de que existe uma natureza intrínseca da realidade" (p. 39), da qual são extraídas premissas universais que serão utilizadas como vetores de um processo interpretativo dedutivista. Tais premissas são tidas como "métodos" de conhecimento, onde seus aplicadores escondem a realidade (o ser do ente), aqui entendida como a complexidade social e, principalmente, a Constituição (p. 80). Ou seja, continuam a olhar o novo com olhos do velho: "Não surpreende, pois, que institutos jurídicos importantes como a arguição de descumprimento de preceito fundamental, o mandado de injunção, a inconstitucionalidade por omissão e tantos outros dispositivos previstos na nova Constituição continuem ineficazes. Também não surpreende que o controle difuso de constitucionalidade não seja uma prática cotidiana dos juristas e dos tribunais. Há certo fascínio pelo Direito infraconstitucional, a ponto de se "adaptar" a Constituição às leis ordinárias... Enfim, continuamos a olhar o novo com os olhos do velho..." (STRECK, 2004, p. 17-80). 


\section{REFERÊNCIAS}

ALEXY, Robert. Colisão de direitos fundamentais e realização de direitos fundamentais no Estado Democrático de Direito. Revista de Direito Administrativo, Rio de Janeiro, 217, p. 67-69, jul./set., 1999.

ARRUDA JÚNIOR, Edmundo Lima de; GONÇALVES, Marcus Fabiano. Fundamentação Ética e Hermenêutica: Alternativas para o Direito. Florianópolis: CESUSC, 2002.

ATIENZA, Manuel. As razões do Direito: teorias da argumentação jurídica. São Paulo: Landy, 2002.

BOBBIO, Norberto. O positivismo jurídico: lições de Filosofia do Direito. São Paulo: Ícone, 1995.

CANOTILHO, José Joaquim Gomes. Direito Constitucional e teoria da Constituição. 4. ed. Coimbra: Almedina, 2001.

CITTADINO, Gisele. Pluralismo, Direito e justiça distributiva: Elementos da filosofia constitucional contemporânea. 3. ed. Rio de Janeiro: Lumen Juris, 2004.

DOTTI, René Ariel. Proteção da vida privada e liberdade de informação: possibilidades e limites. São Paulo: Revista dos Tribunais, 1980.

DUMONT, Louis. O individualismo: uma perspectiva antropológica da ideologia moderna. Rio de Janeiro: Rocco, 1993.

DWORKIN, Ronald. O Império do Direito. Tradução de Jefferson Luiz Camargo. São Paulo: Martins Fontes, 1999.

FARIAS, Edilson Pereira de. Colisão de direitos: a honra, a intimidade, a vida privada e a imagem versus a liberdade de expressão e informação. Porto Alegre: Sérgio Antonio Fabris, 1996.

FREITAS, Juarez. O controle dos atos administrativos e os princípios fundamentais. 4. ed. São Paulo: Malheiros, 2009.

FREITAS, Juarez. Discricionariedade administrativa e o direito fundamental à boa Administração Pública. São Paulo: Malheiros, 2007.

GADAMER, Hans-Georg. Verdade e método I: traços fundamentais de uma hermenêutica filosófica. 7. ed. Tradução de Flávio Paulo Meurer. Petrópolis: Vozes, 2005.

Verdade e método II: complementos e índice. Petrópolis: Vozes, 2002. Tradução de Ênio Paulo Giachini.

HABËrLE, Peter. Hermenêutica Constitucional: a sociedade aberta dos intérpretes da Constituição - contribuição para a interpretação pluralista e "procedimental" da Constituição. Tradução Gilmar Ferreira Mendes. Porto Alegre: Sergio Antonio Fabris, 2002.

HESSE, Konrad. A força normativa da Constituição. Tradução de Gilmar Ferreira Mendes. Porto Alegre: Sergio Antonio Fabris, 1991.

JABUR, Gilberto Haddad. Liberdade de pensamento e direito à vida privada. São Paulo: Revista dos Tribunais, 2000.

JABUR, Gilberto Haddad. Interpretação jurídica. São Paulo: Pontifícia Universidade Católica, 1997.

MACCORMICK, Neil. Argumentação jurídica e teoria do Direito. São Paulo: Martins Fontes, 2006. 
MENÉNDEZ, Ignácio Villaverde. Los Derechos del Público: el derecho a recibir información del artículo 20.1.d) de la Constitución Española de 1978. Madrid: Tecnos, 1995.

MOREIRA NETO, Diogo de Figueiredo. Quatro paradigmas do Direito Administrativo pósmoderno. São Paulo: Fórum, 2008.

SARAMAGO, José. Ensaio sobre a cegueira. São Paulo: Companhia das Letras, 2001.

SARAMAGO, José. Ensaio sobre a lucidez. São Paulo: Companhia das Letras, 2008.

SARLET, Ingo Wolfgang. A eficácia dos direitos fundamentais. 4. ed. Porto Alegre: Livraria do Advogado, 2004.

SCHMITT, Carl. O conceito do político. Petrópolis: Vozes, 1992.

SCHMITT, Rosane Heineck. Direito à informação - liberdade de imprensa $\mathrm{x}$ direito à privacidade. In: SARLET, Ingo Wolfgang (Org.) et al. A Constituição concretizada: construindo pontes com o público e o privado. Porto Alegre: Livraria do Advogado, 2000.

STEIN, Ernildo. Racionalidade e existência: o ambiente hermenêutico e as Ciências Humanas. Ijuí: Unijuí, 2008.

STRECK, Lenio Luiz. Hermenêutica jurídica $e(m)$ crise: uma exploração hermenêutica da construção do Direito. 8. ed. Porto Alegre: Livraria do Advogado, 2009.

STRECK, Lenio Luiz. Hermenêutica, neoconstitucionalismo e o "problema da discricionariedade dos juízes". Disponível em: <http://www.opet.com.br/revista/direito/primeira_edicao/artigo_ Lenio_Luiz_Streck_hermeneutica.pdf> Acesso em: 26 jul. 2010.

Jurisdição constitucional e hermenêutica: uma nova crítica do direito. 2. ed. Rio de Janeiro: Forense, 2004.

Verdade e consenso: Constituição, hermenêutica e teorias discursivas - da possibilidade à necessidade de respostas corretas em Direito. 2. ed. Rio de Janeiro: Lumen Júris, 2008.

STRECK, Lenio Luiz. Disponível em: <http://www.juridicobrasil.com.br/portal/index. php?tipo=7\&cod=2\&id_entrevista=11>. Acesso em 05 nov. 2009.

TRIBE, Laurence; DORF, Michael. Hermenêutica constitucional. Belo Horizonte: Del Rey, 2007.

Recebido: 06/08/2012

Aprovado: 01/12/2013 